\title{
Proximity to a Major Road and Plasma Cytokines in School-Aged Children
}

\author{
Franziska Rosser, MD, MPH, Erick Forno, MD, MPH,, John Brehm, MD, MPH, Yueh-Ying Han, PhD,' \\ Nadia Boutaoui, PhD, Angel Colón-Semidey, MD,2 María Alvarez, MD,2 Edna Acosta-Pérez, PhD, \\ Kristen S. Kurland, BA, John F. Alcorn, PhD, Glorisa Canino, PhD, and Juan C. Celedón, MD, DrPH ${ }^{1}$
}

Traffic-related air pollution (TRAP) may affect immune responses, including those in the $\mathrm{T}_{\mathrm{H}} 2$ and $\mathrm{T}_{\mathrm{H}} 17$ pathways. To examine whether TRAP is associated with plasma level of $\mathrm{T}_{\mathrm{H}} 17-, \mathrm{T}_{\mathrm{H}} 1-$, and $\mathrm{T}_{\mathrm{H}} 2$-related cytokines in children with and without asthma, a cross-sectional study of 577 children (ages 6-14 years) with $(n=294)$ and without $(n=283)$ asthma in San Juan (Puerto Rico) was performed. Residential distance to a major road was estimated using geocoded home addresses for study participants. A panel of 14 cytokines, enriched for the $\mathrm{T}_{\mathrm{H}} 17$ pathway, was measured in plasma. Asthma was defined as physician-diagnosed asthma and current wheeze. Multivariable linear regression was used to examine the association of residential distance to a major road (a marker of TRAP), asthma, and cytokine levels. Among all participating children, residential proximity to a major road was significantly associated with increased plasma level of IL-31, even after adjustment for relevant covariates and correction for multiple testing. The presence of asthma modified the estimated effect of the residential distance to a major road on plasma TNF- $\alpha(P$ for interaction $=0.00047)$. Although living farther from a major road was significantly associated with lower TNF- $\alpha$ level in control subjects, no such decrease was seen in children with asthma. In a direct comparison of cases and control subjects, children with asthma had significantly higher levels of IL-1 $\beta$, IL-22, and IL-33 than control subjects. TRAP is associated with increased levels of proinflammatory cytokines among Puerto Rican children, who belong to an ethnic group with high risk for asthma.

\section{Introduction}

A STHMA IS THE MOST COMMON chronic respiratory disease of childhood in the United States, where $\sim 7$ million children are affected. ${ }^{1}$ Traffic-related air pollution (TRAP) has been implicated in the pathogenesis of childhood asthma. ${ }^{2,3}$ Moreover, TRAP has been associated with eosinophilic inflammation and $\mathrm{T}_{\mathrm{H}} 2$ immune responses, ${ }^{4}$ as well as neutrophilic inflammation, ${ }^{5} \mathrm{~T}_{\mathrm{H}} 17$ cell differentiation, ${ }^{6}$ and increased IL-17 serum levels. ${ }^{7}$

Proximity to a major road, a proxy for TRAP, is associated with asthma and morbidity from asthma in Puerto Rican children. ${ }^{3,8}$ To further understand the potential effects of TRAP on immune responses in Puerto Rican children, we examined the relation between proximity to a major road and plasma cytokines (enriched for the $\mathrm{T}_{\mathrm{H}} 17$ pathway) in a study of 577 children with (cases) and without (control subjects) asthma in San Juan (Puerto Rico). Moreover, we compared plasma cytokine levels between cases and control subjects.

\section{Methods}

\section{Subject recruitment}

From March 2009 to June 2010, children in San Juan were recruited from randomly selected households, as previously described. ${ }^{9}$ In brief, households were selected using a multistage probability sample design. Primary sampling units (PSUs) were randomly selected neighborhood clusters based on the 2000 US Census, and secondary sampling units were randomly selected households within each PSU. On the basis of this design, 7,073 households were selected, and

\footnotetext{
${ }^{1}$ Division of Pulmonary Medicine, Allergy, and Immunology, Department of Pediatrics, Children's Hospital of Pittsburgh of UPMC, University of Pittsburgh, Pittsburgh, Pennsylvania.

${ }^{2}$ Department of Pediatrics, Behavioral Sciences Research Institute, University of Puerto Rico, San Juan, Puerto Rico.

${ }^{3}$ H. John Heinz III College and School of Architecture, Carnegie Mellon University, Pittsburgh, Pennsylvania.

(C) Franziska Rosser et al. 2016; Published by Mary Ann Liebert, Inc. This Open Access article is distributed under the terms of the Creative Commons Attribution Noncommercial License (http://creativecommons.org/licenses/by-nc/4.0/) which permits any noncommercial use, distribution, and reproduction in any medium, provided the original author(s) and the source are credited.
} 
$6,401(90.5 \%)$ were contacted: 1,111 households had one or more children who met inclusion criteria (age 6 to 14 years, 4 Puerto Rican grandparents, and residence in the same household for at least 1 year). Of these 1,111 households, $438(39.4 \%)$ had at least 1 child with asthma (a case, defined as having physician-diagnosed asthma and at least 1 episode of wheeze in the prior year). From these 438 households, 1 child with asthma was selected (at random if there was more than 1 such child). Similarly, only 1 child without asthma (a control subject, having neither physician-diagnosed asthma nor wheeze in the prior year) was randomly selected from the remaining 673 households. To reach our target sample size $(n=700),{ }^{9}$ we attempted to enroll 783 of the 1,111 eligible children. Parents of $105(13.4 \%)$ of these 783 children refused to participate or could not be reached, leaving 678 participants (351 cases and 327 control subjects). There were no significant differences in age, gender, or area of residence between eligible children who did $(n=678)$ and did not $(n=105)$ agree to participate. Of the 678 study participants, $578(85.1 \%)$ had blood samples for plasma cytokine measurements; 577 of these 578 participants also had data on their home address, and were thus included in the current analysis.

\section{Study procedures}

Study participants completed a protocol that included questionnaires and collection of blood samples. One of the child's caretakers [usually $(\sim 93 \%)$ the mother] completed a questionnaire that was slightly modified from one used in the Collaborative Study of the Genetics of Asthma. ${ }^{10} \mathrm{Re}$ sidential distance from the home address of each participant to a major roadway was geocoded (linked) to a 15-digit 2000 US Census Federal Information Processing Standard (FIPS) + block code at the University of Puerto Rico, as previously described. $^{8}$ Using the program ArcMAP10.1 (ArcGIS 10.1; Esri, Redlands, CA), centroids were then created by obtaining $\mathrm{X}$ and $\mathrm{Y}$ coordinates for the center of individual census blocks based on a 2000 US Census map for Puerto Rico. The distance from the residential block centroid of a participant to the nearest major road (defined by Esri 2012 Data and Maps major road layer) was then calculated using the geoprocessing proximity tool "near," which measures the nearest distance "as the crow flies" between 2 features.

A panel of 14 cytokines [enriched for the $T_{H} 17$ pathway, and including interleukin (IL)-1 $\beta$, IL-4, IL-6, IL-10, IL17A, IL-17F, IL-21, IL-22, IL-23, IL-25, IL-31, IL-33, interferon (IFN)- $\gamma$, and tumor necrosis factor (TNF)- $\alpha$ ], was measured in plasma samples using the Bio-Plex Pro Human $\mathrm{T}_{\mathrm{H}} 17$ Cytokine Panel on the Bio-Plex HTF system (Bio-Rad Laboratories, Inc., Hercules, CA) as per the manufacturer's instructions, with all samples measured in duplicate. After assigning a small constant [half the lowest detectable level (Supplementary Table S1; Supplementary Data are available online at www.liebertpub.com/ped)] to nondetectable levels, plasma cytokine levels were $\log 10$ transformed for data analysis, which led to an approximately normal distribution for each cytokine.

Written parental consent and child's assent was obtained for participants in the study, which was approved by the Institutional Review Boards of the University of Puerto Rico
(San Juan, PR), Brigham and Women's Hospital (Boston, MA), and the University of Pittsburgh (Pittsburgh, PA).

\section{Statistical analysis}

Our outcome of interest was log 10 transformed plasma cytokine levels. Our exposure of interest was the residential distance to a major road. The primary analysis was conducted in all study participants [including control subjects and subjects with asthma (defined as physician-diagnosed asthma and $\geq 1$ episode of wheeze in the previous year)].

The following covariates were compared between cases and controls in unadjusted analyses: age, gender, annual household income $[<$ vs. $\geq \$ 15,000$ (near the median household income for Puerto Rico in 2008-2009)], type of health insurance (private or employer-based vs. others), body mass index (BMI) ${ }^{11}$ as a $\mathrm{z}$-score (based on CDC growth charts ${ }^{12}$ ), current environmental tobacco smoke (ETS), ${ }^{13}$ and ETS in early life (in utero or in the first 2 years). The characteristics of children with asthma were compared with those of control subjects using chi square tests for pairs of binary variables, and 2-tailed $t$-tests or Wilcoxon rank-sum test for pairs of binary and continuous variables, as appropriate.

The correlation within each pair of cytokines was tested using a Pearson correlation coefficient. Correlations that were $\geq 0.60$ and were significant at $P<0.01$ were considered strong enough to count as "the same cytokine" for purposes of a modified Bonferroni correction for multiple testing, an approach similar to one widely used to account for correlation among genetic variants in association studies ${ }^{14}$ (eg, if 9 pairs met these criteria, the number of effective tests would be $14-9=5$ ).

Ordinal logistic regression was used for the unadjusted analysis of quartiles of residential distance to a major road and plasma cytokine levels. Linear regression was then used for the multivariable analysis of residential distance to a major road and plasma cytokine levels, adjusting for age, gender, annual household income, current ETS exposure, and asthma (case-control status). For each model, we also tested for a first-order interaction between residential distance to a roadway and asthma. If such interaction was nominally significant $(P<0.05)$, the analysis was conducted separately in cases and control subjects (eg, after stratifying by asthma).

Linear regression was then used to compare plasma cytokine levels between cases and control subjects, adjusting for age, gender, and annual household income. All statistical analyses were performed with SAS software (version 9.4; SAS Institute, Cary, NC).

\section{Results}

The main characteristics of the 577 participating children are shown in Table 1. Compared with control subjects, children with asthma were significantly more likely to be male and to be exposed to current or early life ETS. There were no significant differences in age, residential distance to a major road, BMI z-score, household income, or type of health insurance between children with asthma and control subjects.

Supplementary Figure S1 and Supplementary Table S2 show the pairwise correlations among the measured plasma cytokines. In this analysis, 9 pairs of cytokines had a correlation coefficient $\geq 0.60$ and $P<0.01$, as follows: IL-6 and 
Table 1. Main Characteristics of Study Participants

\begin{tabular}{lccc}
\hline Variables & Controls $(\mathrm{n}=283)$ & Asthma $(\mathrm{n}=294)$ & All children $(\mathrm{n}=577)$ \\
\hline Age, years & $10.5(2.8)$ & $10.1(2.6)$ & $10.3(2.7)$ \\
Male gender & $136(48)$ & $170(58)^{\mathrm{a}}$ & $306(53)$ \\
Distance from a major roadway, meters & $374(297)$ & $333(270)$ & $353(284)$ \\
BMI, z-score & $0.50(1.11)$ & $0.65(1.18)$ & $0.57(1.15)$ \\
Private or employer-based health insurance & $100(35)$ & $88(30)$ & $188(33)$ \\
Annual household income $>\$ 15,000$ & $94(35)$ & $134(32)$ & $185(33)$ \\
Current ETS exposure & $102(36)$ & $148(50)^{\mathrm{a}}$ & $236(41)$ \\
ETS exposure in utero or before age 2 years & $116(41)$ & $264(46)$ \\
\hline
\end{tabular}

Results displayed as mean (SD) for continuous and $n(\%)$ for categorical variables.

${ }^{\mathrm{a}} P<0.05$ for comparison with control subjects.

BMI, body mass index; ETS, environmental tobacco smoke.

IL-25, IL-6 and IFN- $\gamma$, IL-10 and IL-22, IL-10 and IL-25, IL-10 and IL-33, IL17F and IFN- $\gamma$, IL-25 and IL-31, IL-25 and IFN- $\gamma$, and IL-25 and TNF- $\alpha$. Thus, we considered a $P<0.01$ as significant after a Bonferroni correction for 5 independent tests $(P=0.05 / 5=0.01)$.

Table 2 shows the relation between quartiles of residential distance to a major road and plasma levels of each cytokine. In this analysis, distance to a major road was linearly associated with lower levels of 5 cytokines at $P<0.05$ : IL-4, IL-6, IL-10, IL-17F, and IL-31. After correction for multiple testing, the association was borderline statistically significant for IL-17F $(P=0.01)$ and statistically significant for IL-31 $(P=0.004)$.

Table 3 shows the results of the linear regression analysis of residential distance to a major road and plasma cytokine levels, after adjustment for age, gender, annual household income, current ETS, and asthma (case-control status). In this analysis, distance to a major road remained significantly associated with lower level of IL-31 $(P=0.007)$. An interaction between residential distance to a road and casecontrol status (asthma) was significant for plasma levels of TNF- $\alpha(P=0.0047)$, but not for any other plasma cytokine level. Thus, the analysis of TNF- $\alpha$ was stratified by the presence or absence of asthma (Fig. 1). In this stratified analysis, residential distance was associated with lower TNF- $\alpha$ in control subjects $(\beta=-0.011,95 \% \mathrm{CI}=-0.021$ to $-0.001, P=0.03)$, but not in cases $(P=0.08)$.

Because of strong co-linearity, we could not include both household income and type of health insurance in the multivariable models. However, we obtained very similar results when the multivariate models were adjusted for type of health insurance instead of household income (data not shown).

Finally, we compared plasma cytokine levels between children with and without asthma (Supplementary Table S3). Compared with control subjects, children with asthma had higher plasma levels of IL-1 $\beta$, IL-17F, IL-22, and IL-33 $(P<0.01$ in all instances $)$. After adjustment for age, gender, and current ETS, these differences were nominally significant for IL-1 $\beta$, IL-22, IL-31, and IL-33; after correction for multiple testing, all but IL-31 remained significant (Table 4).

\section{Discussion}

To our knowledge, this is the first study to examine residential distance to a major road and a panel of plasma

Table 2. Distance From a Major Roadway (IN Quartiles) and Plasma Cytokine Levels in Study Participants $(N=577)$

\begin{tabular}{|c|c|c|c|c|c|}
\hline $\begin{array}{l}\text { Log10 }(\mathrm{pg} / \mathrm{mL}) \\
\text { selected cytokine } \\
\text { level }\end{array}$ & $\begin{array}{c}\text { Quartile 1 } \\
(<172 \mathrm{~m}), \mathrm{n}=131\end{array}$ & $\begin{array}{c}\text { Quartile 2 } \\
(172-220 \mathrm{~m}), \mathrm{n}=161\end{array}$ & $\begin{array}{c}\text { Quartile 3 } \\
(221-496 \mathrm{~m}), \mathrm{n}=151\end{array}$ & $\begin{array}{c}\text { Quartile } 4 \\
(>496 \mathrm{~m}), \mathrm{n}=134\end{array}$ & $\mathrm{P}$ for trend \\
\hline IL $1 \beta$ & $-0.07(0.42)$ & $-0.19(0.62)$ & $-0.10(0.57)$ & $-0.21(0.56)$ & 0.15 \\
\hline IL 4 & $0.58(0.93)$ & $0.71(0.89)$ & 0.35 & $0.46(0.96)$ & 0.04 \\
\hline IL 6 & $0.83(0.46)$ & $0.79(0.56)$ & $0.72(0.58)$ & $0.71(0.59)$ & 0.04 \\
\hline IL 10 & $0.67(1.01)$ & $0.64(1.04)$ & $0.54(0.97)$ & $0.41(1.04)$ & 0.03 \\
\hline IL 17A & $0.70(0.84)$ & $0.48(0.91)$ & $0.75(0.80)$ & $0.59(0.81)$ & 0.98 \\
\hline IL 17F & $0.99(1.06)$ & $1.23(0.96)$ & $0.74(1.08)$ & $0.82(1.09)$ & 0.01 \\
\hline IL 21 & $0.64(0.77)$ & $0.58(0.78)$ & $0.57(0.74)$ & $0.47(0.70)$ & 0.06 \\
\hline IL 22 & $0.41(0.91)$ & $0.25(0.96)$ & $0.45(0.93)$ & $0.30(0.93)$ & 0.80 \\
\hline IL 23 & $0.09(0.59)$ & $-0.01(0.39)$ & $0.15(0.62)$ & $0.09(0.57)$ & 0.37 \\
\hline IL 25 & $0.66(0.32)$ & $0.66(0.46)$ & $0.60(0.37)$ & $0.58(0.42)$ & 0.06 \\
\hline IL 31 & $1.32(0.87)$ & $1.49(0.80)$ & $1.17(1.00)$ & $1.11(1.02)$ & 0.004 \\
\hline IL 33 & $1.75(0.60)$ & $1.58(0.84)$ & $1.76(0.53)$ & $1.61(0.76)$ & 0.49 \\
\hline IFN $\gamma$ & $0.79(1.08)$ & $1.02(1.10)$ & $0.59(1.12)$ & $0.69(1.10)$ & 0.07 \\
\hline $\mathrm{TNF} \alpha$ & $0.85(0.23)$ & $0.84(0.23)$ & $0.83(0.23)$ & $0.80(0.27)$ & 0.13 \\
\hline
\end{tabular}

Results presented as mean (SD).

$P$ value for trend obtained using unadjusted ordinal regression. 
Table 3. Linear Regression Analysis of Residential Distance to a Major Road and Plasma Cytokines in 577 Study Participants

\begin{tabular}{|c|c|c|c|c|}
\hline \multirow[b]{2}{*}{ Plasma cytokine level } & \multicolumn{2}{|l|}{ Unadjusted } & \multicolumn{2}{|l|}{ Adjusted $^{\mathrm{a}}$} \\
\hline & $\beta(95 \% C I)$ & $\mathrm{P}$ & $\beta(95 \% C I)$ & $\mathrm{P}$ \\
\hline IL-1 $\beta$ & $-0.010(-0.026$ to 0.006$)$ & 0.22 & $-0.011(-0.027$ to 0.005$)$ & 0.19 \\
\hline IL-4 & $-0.023(-0.050$ to 0.004$)$ & 0.09 & $-0.03(-0.05$ to 0.002$)$ & 0.07 \\
\hline IL-6 & $-0.013(-0.029$ to 0.003$)$ & 0.10 & $-0.011(-0.027$ to 0.005$)$ & 0.16 \\
\hline IL-10 & $-0.029(-0.058$ to 0.0002$)$ & 0.05 & $-0.030(-0.059$ to -0.0001$)$ & 0.047 \\
\hline IL-17A & $0.004(-0.021$ to 0.026$)$ & 0.76 & $0.005(-0.020$ to 0.029$)$ & 0.72 \\
\hline IL-17F & $-0.034(-0.065$ to -0.004$)$ & $\mathbf{0 . 0 3}$ & $-0.030(-0.061$ to 0.0004$)$ & 0.05 \\
\hline IL-21 & $-0.016(-0.037$ to 0.006$)$ & 0.15 & $-0.016(-0.038$ to 0.006$)$ & 0.15 \\
\hline IL-22 & $0.0002(-0.027$ to 0.027$)$ & 0.99 & $0.0002(-0.027$ to 0.028$)$ & 0.99 \\
\hline IL-23 & $0.010(-0.006$ to 0.026$)$ & 0.22 & $0.012(-0.004$ to 0.028$)$ & 0.14 \\
\hline IL-25 & $-0.010(-0.021$ to 0.002$)$ & 0.10 & $-0.008(-0.020$ to 0.004006$)$ & 0.17 \\
\hline IL-31 & $-0.038(-0.064$ to -0.011$)$ & 0.006 & $-0.038(-0.065$ to -0.011$)$ & 0.007 \\
\hline IL-33 & $-0.005(-0.026$ to 0.015$)$ & 0.60 & $-0.008(-0.028$ to 0.013$)$ & 0.46 \\
\hline IFN- $\gamma$ & $-0.031(-0.063$ to 0.001$)$ & 0.06 & $-0.025(-0.057$ to 0.007$)$ & 0.13 \\
\hline TNF- $\alpha$ & $-0.005(-0.011$ to 0.002$)$ & 0.19 & $-0.011(-0.02$ to -0.002$)$ & $\mathbf{0 . 0 1}^{\mathrm{b}}$ \\
\hline
\end{tabular}

Bold indicates statistical significance at alpha level 0.05 .

${ }^{a}$ Adjusted for age, gender, household income, current ETS exposure, and case-control status.

${ }^{\mathrm{b}}$ For TNF- $\alpha, P$ value is from main effects in models that also include the interaction term (interaction term $P=0.0047$ for TNF- $\alpha$; nonsignificant, and thus removed from the model, for all other cytokines).

cytokines (enriched for the $\mathrm{T}_{\mathrm{H}} 17$ pathway) in children with and without asthma.

Among Puerto Rican children, residential proximity to a major road is significantly associated with increased plasma levels of IL-31 (implicated in $\mathrm{T}_{\mathrm{H}} 2$ immune responses). There was also suggestive, but nonstatistically significant evidence of an association between proximity to a major road and higher levels of both IL17F (implicated in $\mathrm{T}_{\mathrm{H}} 17$ immune responses) and IL-10 (involved in pathways related to $\mathrm{T}_{\text {regs }}, \mathrm{T}_{\mathrm{H}} 2$, and $\mathrm{T}_{\mathrm{H}} 17$ immune responses). Moreover, we report that asthma modifies the estimated effect of proximity to a major road on plasma level of TNF- $\alpha$. Whereas living further away from a major road was associated with a lower level of TNF- $\alpha$ in control subjects, there was no significant association between road prox- imity and either IL-4 or TNF- $\alpha$ level in children with asthma.

Our results suggest that TRAP increases plasma levels of proinflammatory cytokines, including $\mathrm{T}_{\mathrm{H}} 2$ (eg, IL-31) and $\mathrm{T}_{\mathrm{H}} 17$ (eg, IL17-F) cytokines among subjects in an ethnic group that is disproportionately affected with asthma (Puerto Ricans). These findings are generally consistent with those of a recent study in mice, which reported that exposure to urban particulate matter (PM) is associated with higher serum levels of IL-4 and IL-17F, although that study reported lower serum levels of IL-10. ${ }^{15}$

IL-31 is a relatively novel cytokine that is induced by IL4 , is produced by $T_{H} 2$ cells (but not $T_{H} 1, T_{H} 17$, or $T_{H} 22$ ), and promotes $\mathrm{T}_{\mathrm{H}}$ 2-type inflammation. ${ }^{16}$ IL-31 level has been associated with multiple atopic and hypersensitivity
FIG. 1. Multivariate regression analysis of proximity to a major road and TNF- $\alpha$, in control subjects and in children with asthma. All models were adjusted for age, gender, current environmental tobacco smoke exposure, and annual household income.
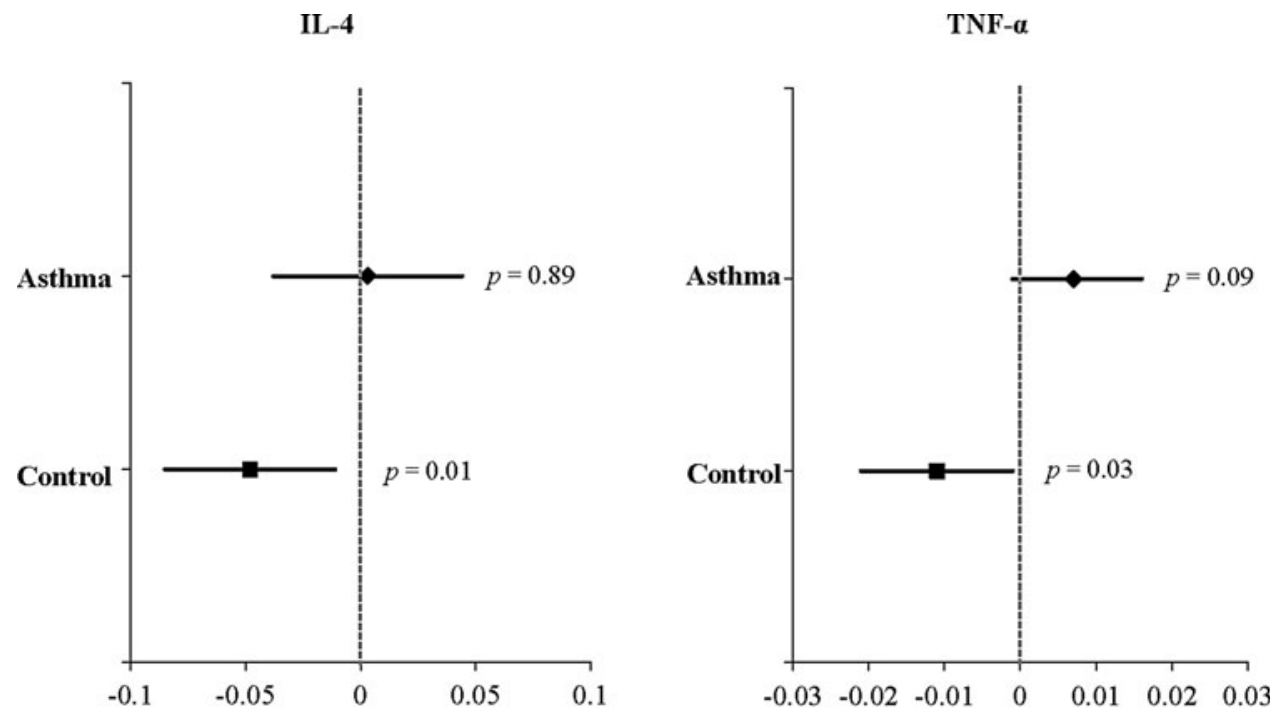
Table 4. Linear Regression Analysis of Plasma Cytokines and Asthma in 577 Study Participants

\begin{tabular}{|c|c|c|c|c|}
\hline \multirow[b]{2}{*}{ Plasma cytokine } & \multicolumn{2}{|c|}{ Unadjusted } & \multicolumn{2}{|c|}{ Adjusted $^{\mathrm{a}}$} \\
\hline & OR $(95 \% C I)$ & $\mathrm{P}$ & OR $(95 \% C I)$ & $\mathrm{P}$ \\
\hline IL-1 $\beta$ & $1.65(1.21$ to 2.26$)$ & 0.001 & $1.63(1.18$ to 2.25$)$ & 0.003 \\
\hline IL-4 & $0.95(0.80$ to 1.13$)$ & 0.56 & $0.98(0.82$ to 1.17$)$ & 0.82 \\
\hline IL-6 & $1.09(0.81$ to 1.47$)$ & 0.56 & $1.23(0.90$ to 1.68$)$ & 0.20 \\
\hline IL-10 & $1.13(0.96$ to 1.33$)$ & 0.13 & $1.18(0.994$ to 1.39$)$ & 0.06 \\
\hline IL-17A & $1.17(0.97$ to 1.42$)$ & 0.11 & $1.17(0.96$ to 1.43$)$ & 0.13 \\
\hline IL-17F & $0.82(0.71$ to 0.96$)$ & 0.01 & $0.86(0.74$ to 1.02$)$ & 0.07 \\
\hline IL-21 & $1.19(0.96$ to 1.48$)$ & 0.12 & $1.22(0.97$ to 1.53$)$ & 0.09 \\
\hline IL-22 & $1.28(1.08$ to 1.53$)$ & 0.006 & $1.32(1.10$ to 1.58$)$ & 0.003 \\
\hline IL-23 & $0.83(0.62$ to 1.13$)$ & 0.23 & $0.84(0.61$ to 1.14$)$ & 0.26 \\
\hline IL-25 & $1.05(0.70$ to 1.57$)$ & 0.83 & $1.19(0.78$ to 1.82$)$ & 0.41 \\
\hline IL-31 & $1.16(0.97$ to 1.38$)$ & 0.11 & $1.20(1.00$ to 1.44$)$ & 0.048 \\
\hline IL-33 & $1.45(1.13$ to 1.87$)$ & 0.003 & $1.45(1.13$ to 1.87$)$ & 0.004 \\
\hline IFN- $\gamma$ & $0.87(0.75$ to 1.01$)$ & 0.07 & $0.92(0.79$ to 1.07$)$ & 0.29 \\
\hline TNF $\alpha$ & $1.28(0.64$ to 2.55$)$ & 0.48 & $1.51(0.70$ to 3.24$)$ & 0.29 \\
\hline
\end{tabular}

Bold indicates statistical significance at alpha level 0.05 .

${ }^{\mathrm{a}}$ Adjusted for age, gender, household income, and current ETS exposure.

conditions, including asthma, eczema, ${ }^{17}$ allergic rhinitis, ${ }^{18}$ mastocytosis, ${ }^{19}$ and pruritus in a variety of disorders. ${ }^{20-22}$ However, little is known about environmental factors that influence IL-31 production; to our knowledge this is the first study to show that TRAP is associated with increased IL-31 in plasma.

TNF- $\alpha$ has been widely implicated in asthma. ${ }^{23-25}$ In vitro or animal studies have shown that exposure to ozone, diesel exhaust particles, or near-roadway PM can induce production of TNF- $\alpha{ }^{26,27}$ Similar results have been found in bronchoalveolar fluid from mice exposed to high concentrations of $\mathrm{PM}_{2.5} \cdot{ }^{4}$ Interestingly, we found that TNF$\alpha$ decreased in children without asthma who live farther from major roadways, whereas no such decrease was seen among children with asthma. Thus, we speculate that asthma may abrogate the beneficial effect of living farther from areas with high TRAP.

Consistent with our previous finding of a predominance of atopic or allergic asthma among Puerto Rican children, plasma levels of IL-22 and IL-33 (implicated in $\mathrm{T}_{\mathrm{H}} 2$ immune responses) and IL-1 $\beta$ (a proinflammatory cytokine) were significantly higher in cases than in control subjects $(P<0.01$ in all instances). There was also a nonstatistically significant trend for a higher level of IL-31 (implicated in $\mathrm{T}_{\mathrm{H}} 2$ immune responses) in cases than in control subjects $(P<0.05)$.

We recognize several limitations of our study. First, we lack data on specific pollutants, and thus cannot examine their individual effects on cytokine levels. However, examining TRAP by residential proximity to a major road integrates exposure to a complex milieu of pollutants, ${ }^{28}$ some of which (ex. nitrogen dioxide, PM and ozone) have been implicated in the pathogenesis of asthma and severe asthma exacerbations. ${ }^{29,30}$ Second, repeated cytokine measurements may offer a more complete picture of immune responses than a single measurement, because of better accounting for intrasubject variability ${ }^{31-33}$ or effects from acute exposures. ${ }^{31,34}$ Third, we had no cytokine measurements in the airways, thus limiting our assessment of potential effects of TRAP on airway inflammation. ${ }^{35}$ Fourth, we cannot establish temporality or causation in this cross- sectional study. Fifth, we had limited statistical power to detect modest to moderate associations, due to both sample size and the need to correct for multiple testing. Sixth, we lacked data on airway responsiveness. However, our definition of asthma has been extensively used in epidemiologic studies in children, in whom it is well correlated with increased airway responsiveness to methacholine. Finally, we did not use a usual Bonferroni correction, which would adjust for all 14 cytokines measured. On the other hand, our strategy to adjust for 5 noncorrelated cytokine levels is both reasonable and similar to a broadly used approach to adjust for multiple testing in the context of correlated genetic markers (eg, linkage disequilibrium-adjusted Bonferroni correction ${ }^{14}$ ). Such approach is less stringent, resulting in a lower probability of a Type II error (eg, falsely negative results).

In summary, our findings suggest that roadway proximity, a marker of TRAP, is associated with increased levels of several proinflammatory cytokines in Puerto Rican children. Our results warrant follow up in longitudinal studies of under-served children with and without asthma, including Puerto Ricans.

\section{Acknowledgments}

This work was supported by grants HL079966 and HL117191 from the US National Institutes of Health, and by The Heinz Endowments. Dr Forno's contribution was funded in part by grants HL125666 from the US NIH, and the Children's Hospital of Pittsburgh of UPMC. None of the funding sponsors had any role in study design, data analysis, or article preparation or approval. Dr. Celedón had full access to all of the data and takes responsibility for the integrity and accuracy of the analysis. The authors thank all participating children and their families for their invaluable contribution to the study.

\section{Authors' Contributions}

Conception and study design: F.R., G.C., and J.C.C.; Data collection: N.B., A.C.-S., M.A., and E.A.-P; Data 
analysis and interpretation: F.R., E.F., J.B. Y.-Y.H., K.S.K., and J.F.A.; drafting of the article for intellectual content: F.R. and J.C.C. All authors approved the final version of the article prior to submission.

\section{Author Disclosure Statement}

No competing financial interests exist.

\section{References}

1. Akinbami LJ, Moorman JE, Bailey C, et al. Trends in asthma prevalence, health care use, and mortality in the United States, 2001-2010. NCHS Data Brief 2012:1-8.

2. Brown MS, Sarnat SE, DeMuth KA, et al. Residential proximity to a major roadway is associated with features of asthma control in children. PLoS One 2012; 7:e37044.

3. Nishimura KK, Galanter JM, Roth LA, et al. Early-life air pollution and asthma risk in minority children. The GALA II and SAGE II studies. Am J Respir Crit Care Med 2013; 188:309-318.

4. Zhang X, Zhong W, Meng Q, et al. Ambient PM2.5 exposure exacerbates severity of allergic asthma in previously sensitized mice. J Asthma 2015; 52:785-794.

5. McCreanor J, Cullinan P, Nieuwenhuijsen MJ, et al. Respiratory effects of exposure to diesel traffic in persons with asthma. N Engl J Med 2007; 357:23482358.

6. van Voorhis M, Knopp S, Julliard W, et al. Exposure to atmospheric particulate matter enhances Th17 polarization through the aryl hydrocarbon receptor. PLoS One 2013; 8:e82545.

7. Brandt EB, Kovacic MB, Lee GB, et al. Diesel exhaust particle induction of IL-17A contributes to severe asthma. J Allergy Clin Immunol 2013; 132:1194-1204.e2.

8. Rosser F, Brehm JM, Forno E, et al. Proximity to a major road, vitamin D insufficiency, and severe asthma exacerbations in Puerto Rican children. Am J Respir Crit Care Med 2014; 190:1190-1193.

9. Rosas-Salazar C, Ramratnam SK, Brehm JM, et al. Prematurity, atopy, and childhood asthma in Puerto Ricans. J Allergy Clin Immunol 2014; 133:357-362.

10. Blumenthal MN, Banks-Schlegel S, Bleecker ER, Marsh DG, Ober C. Collaborative studies on the genetics of asthma-National Heart, Lung and Blood Institute. Clin Exp Allergy 1995; 25 Suppl 2:29-32.

11. Perez-Perdomo R, Perez-Cardona C, Disdier-Flores O, Cintron Y. Prevalence and correlates of asthma in the Puerto Rican population: behavioral risk factor surveillance system, 2000. J Asthma 2003; 40:465-474.

12. Kuczmarski RJ, Ogden CL, Grummer-Strawn LM, et al. CDC growth charts: United States. Adv Data 2000:1-27.

13. Freeman NC, Schneider D, McGarvey P. Household exposure factors, asthma, and school absenteeism in a predominantly Hispanic community. J Expo Anal Environ Epidemiol 2003; 13:169-176.

14. McCarthy MI, Abecasis GR, Cardon LR, et al. Genomewide association studies for complex traits: consensus, uncertainty and challenges. Nat Rev Genet 2008; 9:356369.

15. Saunders V, Breysse P, Clark J, Sproles A, Davila M, Wills-Karp M. Particulate matter-induced airway hyperre- sponsiveness is lymphocyte dependent. Environ Health Perspect 2010; 118:640-646.

16. Stott B, Lavender P, Lehmann S, Pennino D, Durham S, Schmidt-Weber CB. Human IL-31 is induced by IL-4 and promotes $\mathrm{TH} 2$-driven inflammation. J Allergy Clin Immunol 2013; 132:446-454.e5.

17. Kato A, Fujii E, Watanabe T, et al. Distribution of IL-31 and its receptor expressing cells in skin of atopic dermatitis. J Dermatol Sci 2014; 74:229-235.

18. Liu W, Luo R, Chen $\mathrm{Y}$, et al. Interleukin-31 promotes helper T cell type-2 inflammation in children with allergic rhinitis. Pediatr Res 2015; 77:20-28.

19. Hartmann K, Wagner N, Rabenhorst A, et al. Serum IL-31 levels are increased in a subset of patients with mastocytosis and correlate with disease severity in adult patients. J Allergy Clin Immunol 2013; 132:232235.

20. Cedeno-Laurent F, Singer EM, Wysocka M, et al. Improved pruritus correlates with lower levels of IL-31 in CTCL patients under different therapeutic modalities. Clin Immunol 2015; 158:1-7.

21. Ko MJ, Peng YS, Chen HY, et al. Interleukin-31 is associated with uremic pruritus in patients receiving hemodialysis. J Am Acad Dermatol 2014; 71:11511159.e1.

22. Singer EM, Shin DB, Nattkemper LA, et al. IL-31 is produced by the malignant $\mathrm{T}$-cell population in cutaneous $\mathrm{T}$ Cell lymphoma and correlates with CTCL pruritus. J Invest Dermatol 2013; 133:2783-2785.

23. Zhu S, Chan-Yeung $M$, Becker $A B$, et al. Polymorphisms of the IL-4, TNF-alpha, and Fcepsilon RIbeta genes and the risk of allergic disorders in at-risk infants. Am J Respir Crit Care Med 2000; 161:16551659.

24. Al-Daghri NM, Abd-Alrahman S, Draz H, et al. Increased IL-4 mRNA expression and poly-aromatic hydrocarbon concentrations from children with asthma. BMC Pediatr 2014; 14:17.

25. Brown SD, Brown LA, Stephenson S, et al. Characterization of a high TNF-alpha phenotype in children with moderate-to-severe asthma. J Allergy Clin Immunol 2015; 135:1651-1654.

26. Wu W, Muller R, Berhane $\mathrm{K}$, et al. Inflammatory response of monocytes to ambient particles varies by highway proximity. Am J Respir Cell Mol Biol 2014; 51:802-809.

27. Kafoury RM, Madden MC. Diesel exhaust particles induce the over expression of tumor necrosis factor-alpha (TNF-alpha) gene in alveolar macrophages and failed to induce apoptosis through activation of nuclear factorkappaB (NF-kappaB). Int J Environ Res Public Health 2005; 2:107-113.

28. Pratt GC, Parson K, Shinoda N, et al. Quantifying traffic exposure. J Expo Sci Environ Epidemiol 2014; 24:290296.

29. Salam MT, Islam T, Gilliland FD. Recent evidence for adverse effects of residential proximity to traffic sources on asthma. Curr Opin Pulm Med 2008; 14:3-8.

30. Auerbach A, Hernandez ML. The effect of environmental oxidative stress on airway inflammation. Curr Opin Allergy Clin Immunol 2012; 12:133-139.

31. Nordenhall C, Pourazar J, Ledin MC, Levin JO, Sandstrom T, Adelroth E. Diesel exhaust enhances airway responsiveness in asthmatic subjects. Eur Respir J 2001; 17:909915. 
32. Sarinho ES, Azoubel-Antunes A, Rego MJ, et al. Evaluation of Th17-related cytokines and IFNgamma production from blood mononuclear cells of moderate and severe asthmatic children reveals methylprednisolone does not decrease IL-22 levels. J Asthma 2015; 52:227-231.

33. Pukelsheim K, Stoeger T, Kutschke D, Ganguly K, Wjst M. Cytokine profiles in asthma families depend on age and phenotype. PLoS One 2010; 5:e14299.

34. Behndig AF, Larsson N, Brown JL, et al. Proinflammatory doses of diesel exhaust in healthy subjects fail to elicit equivalent or augmented airway inflammation in subjects with asthma. Thorax 2011; 66:12-19.

35. Hollander C, Sitkauskiene B, Sakalauskas R, Westin U, Janciauskiene SM. Serum and bronchial lavage fluid concentrations of IL-8, SLPI, sCD14 and sICAM-1 in patients with COPD and asthma. Respir Med 2007; 101: 1947-1953.

Address correspondence to:

Juan C. Celedón, $M D, D r P H$

Division of Pulmonary Medicine, Allergy and Immunology

Department of Pediatrics

Children's Hospital of Pittsburgh of UPMC

University of Pittsburgh 4401 Penn Avenue

Pittsburgh, PA 15224

E-mail: juan.celedon@chp.edu

Received for publication March 18, 2016; accepted after revision May 26, 2016. 